\title{
Ipratropium bromide and airways function in wheezy infants
}

\author{
A PRENDIVILLE, S GREEN, AND M SILVERMAN
}

Department of Paediatrics and Neonatal Medicine, Royal Postgraduate Medical School, London

SUMMARY The airway response to nebulised ipratropium bromide was studied in 17 chronically or recurrently wheezy infants aged 4-15 months. The peripheral airway response was assessed by the change in maximum flow at functional residual capacity (V́max FRC) and the upper and central airway response by the change in specific airways resistance. The significant reduction in specific airways resistance after treatment with ipratropium bromide signified an improvement in central and upper airway function. No change was found, however, in $\dot{V} \max$ FRC and hence in peripheral airway function. It seems that, as in older subjects, inhaled antimuscarinic, anticholinergic drugs have their maximum effect on the large airways, and this may explain their lack of effect in the management of acute bronchiolitis.

Evidence for the effectiveness of antimuscarinic, anticholinergic agents, such as ipratropium bromide, in the management of wheezy infants remains controversial. Given as a single dose, ipratropium bromide has been shown to diminish the airways resistance, as measured in the lung function laboratory, ${ }^{1}$ but has not been shown to confer any important clinical benefit during a small clinical trial. $^{2}$

An explanation for this discrepancy is to be found in the physiological methods that have been used to assess the airway response and the probable site of maximum effect of anticholinergic agents in the airway. In the past, techniques for measuring airways resistance during quiet breathing in infancy have been predominantly influenced by changes in the upper airways (nasopharynx and glottis) and the large central airways. Measurements of airways resistance are fairly insensitive to changes in peripheral airways function. The maximum site of action of inhaled anticholinergic agents is on central airways, ${ }^{3}$ coinciding with the site of maximum density of muscarinic receptors. ${ }^{4}$ Thus, although improvement in the value of airways resistance might be expected to infer clinical benefit, without an improvement in peripheral airway function such benefit might not occur.

To test this hypothesis we studied 17 infants and obtained measurements of airways resistance, an index of upper and central airways function, and measurements of maximum expiratory flow at functional residual capacity ( $\operatorname{Vmax}$ FRC), an index of peripheral airways function. ${ }^{56}$ Measurements were made before and after the administration of nebulised ipratropium bromide, a poorly absorbed antimuscarinic, anticholinergic agent, in a group of wheezy infants.

\section{Patients and methods}

Patients. Seventeen infants (mean age 7.3 months, range 4-15 months) with a history of wheezing of between one and seven months were studied. Twelve infants had persistent wheezing and five recurrent episodes of wheezing, with an interval phase varying from one day to five months between acute attacks. Thirteen of the infants were wheezy on the study day.

Eight of the infants had a first degree family history of asthma or eczema. The parents of eight infants were smokers. Five infants had previously been treated with ipratropium bromide, and two had been reported to show clinical benefit. No infant had received treatment with bronchodilator within 24 hours of testing. Before the study, each child was sedated with chloral hydrate $100 \mathrm{mg} / \mathrm{kg}$ body weight.

The approval of the local ethics committee and informed parental consent were obtained for all studies, which were carried out as part of the clinical assessment of the children.

\section{Methods.}

Lung function tests

After the infants had fallen asleep they were placed 
in a whole body plethysmograph, and baseline measurements of thoracic gas volume and initial inspiratory airway resistance were obtained as previously described. ${ }^{78}$ Reference values were obtained from previous work from this laboratory. ${ }^{9}$ As some controversy exists about the validity of measurement of thoracic gas volume in wheezy individuals ${ }^{1011}$ specific airway resistance, the product of thoracic gas volume and initial inspiratory airways resistance, was used as a more reliable index of baseline lung-function. ${ }^{11} 12$

The infants were then placed in an inflatable polythene jacket, ${ }^{6}$ which extended from the shoulders to the upper thighs, with a cut away at the neck to avoid putting pressure on the trachea. Flow and its integral volume were measured using a heated screen pneumotachograph (diameter $19 \mathrm{~mm}$ and linear to $40 \mathrm{l} / \mathrm{min}$ ) with accompanying flow transducer (Validyne MP45) attached to a facemask (Rendell Baker), which was sealed around the nose and mouth with silicone putty. By rapidly inflating the jacket at end inspiration to pressures of between 30 and $40 \mathrm{~cm} \mathrm{H}_{2} \mathrm{O}$, partial expiratory flow volume curves were produced and measurements of peak expiratory flow rate from end inspiration. and maximum flow at functional residual capacity ( $\dot{\mathrm{V}} \mathrm{max}$ FRC) were obtained as previously described. ${ }^{6}$ Reference values were obtained from previous work. ${ }^{6}$

\section{Bronchodilator administration}

After six to eight baseline flow volume curves had been obtained $2.5 \mathrm{ml}$ of a control solution of nebulised normal saline was administered, using a Turret nebuliser, the output of which was $2 \cdot 1 \mathrm{ml} / \mathrm{min}$ at a flow rate of $6 \mathrm{l} / \mathrm{min}$. After 10 minutes a further set of partial expiratory flow volume curves was obtained. Nebulised ipratropium bromide $(250 \mathrm{mcg}$ in $2.5 \mathrm{ml}$ normal saline) was then administered and after 20 minutes repeat flow volume curves and measurements of thoracic gas volume and airways resistance were obtained. Eight patients awoke before the final set of plethysmographic measurements were completed, due to the duration of the procedures. One measurement of thoracic gas volume after and two airways resistance measurements before treatment with ipratropium bromide were technically invalid and not reported. There were therefore only eight complete sets of measurement of specific airways resistance available.

Statistical analysis. Paired $t$ tests were used to assess the significance of the effect of ipratropium bromide on the lung function measurements obtained where paired data were available. Individual responsiveness to ipratropium bromide was assessed as a change that was outside the confidence limits for Vmax FRC or airways resistance. ${ }^{69}$

\section{Results}

Baseline lung function data confirmed the presence of pronounced airways obstruction (Table 1). All infants had raised baseline values of airways resistance and specific airways resistance, the mean values for the group as a whole being $470 \%$ and $530 \%$ of the predicted reference values. ${ }^{9}$ Baseline Vmax FRC and peak expiratory flow rate when normalised for body length were $49 \%$ and $80 \%$ of their respective reference values. ${ }^{6}$ After treatment with nebulised saline there was a small but insignificant drop in both peak expiratory flow rate and $\dot{V} \max$ FRC in the group as a whole (Table 2). Treatment with nebulised ipratropium bromide failed to improve the mean value of $V \max$ FRC. Although the mean value of peak expiratory flow rate increased from 286 to $305 \mathrm{ml} / \mathrm{sec}$, this increase failed to reach significance $(t=1 \cdot 9, p=0 \cdot 08)$. In the eight infants who had complete sets of measurements of thoracic gas volume and airways resistance before and after treatment with ipratropium bromide there was a significant drop in the mean value of specific airways resistance from 14.7 to 8.7 $\mathrm{cm} \mathrm{H}_{2} \mathrm{O} / \mathrm{sec}(\mathrm{t}=2 \cdot 8, \mathrm{p}=0 \cdot 027)$.

Most individual infants failed to show any significant change in Vmax FRC or peak expiratory flow

Table 1 Baseline lung function ( $\%$ of reference value) in infants with wheeze

\begin{tabular}{lll}
\hline & $n$ & Mean (SD) \\
\hline Thoracic gas volume & 17 & $105(47)$ \\
Airway resistance & 15 & $470(286)$ \\
Specific airway resistance & 15 & $530(417)$ \\
Vmax FRC & 17 & $49(48)$ \\
Peak flow rate & 17 & $80(27)$ \\
\hline
\end{tabular}

Vंmax FRC=Maximum flow at functional residuc capacity during forced expiration.

Table 2 Response to nebulised ipratropium bromide compared with saline in infants with wheeze

\begin{tabular}{lllll}
\hline & $n$ & Control & Saline & Ipratropium \\
\hline $\begin{array}{l}\text { Vmax FRC }(\mathrm{ml} / \mathrm{sec}) \\
\text { Peak expiratory flow } \\
\quad \text { rate }(\mathrm{ml} / \mathrm{sec})\end{array}$ & 17 & $105(114)$ & $103(107)$ & $101(100)$ \\
$\begin{array}{l}\text { Specific airways } \\
\text { resistance } \\
\left(\mathrm{cm} \mathrm{H}_{2} \mathrm{O} / \mathrm{sec}\right)\end{array}$ & 8 & $286(110)$ & $281(104)$ & $305(113)$ \\
\hline
\end{tabular}

$\dot{V} \max F R C=$ Maximum flow at functional residue capacity.

*Significantly different from pretreatment value $(p<0 \cdot 05)$ based on a paired $t$ test: no other differences were significant. 
Ipratropium bromide and airways function in wheezy infants

Table 3 Individual responses to treatment with saline or ipratropium bromide in infants with wheeze

\begin{tabular}{|c|c|c|c|c|c|c|}
\hline & \multicolumn{3}{|l|}{ Saline } & \multicolumn{3}{|c|}{ Ipratropium } \\
\hline & Improved & No change & Worse & Improved & No change & Worse \\
\hline$\dot{V} \max$ FRC & 2 & 13 & 2 & 2 & 14 & 1 \\
\hline Peak expiratory flow rate & - & 15 & 2 & 5 & 12 & - \\
\hline Airways resistance & - & - & - & 5 & 3 & 0 \\
\hline
\end{tabular}

$\dot{V} \max F R C=$ Maximum flow at functional residue capacity.

rate after treatment with saline or ipratropium, although five $(29 \%)$ had a significant increase in peak expiratory flow rate after ipratropium (Table 3 ). Of the eight patients who had complete sets of measurements of airways resistance before and after treatment with ipratropium, five had a significant reduction in resistance, while the others were unchanged. Three of these infants were among the five who had an increase in peak expiratory flow rate.

\section{Discussion}

To reassess the role of anticholinergic agents in the management of wheezy infants, we set out to determine the site of maximum effect of nebulised ipratropium bromide. We used specific airways resistance as an indicator of overall (largely upper and central) airways function and Vmax FRC as a measure of the peripheral airways response. There was significant reduction in specific airways resistance after treatment with ipratropium bromide, indicating an overall reduction in airways obstruction, but no improvement in the peripheral airways function as determined by $\dot{V} \max$ FRC. Peak expiratory flow rate, generally thought to be influenced by large airways function, tended to improve after treatment with ipratropium.

These findings would tend to support the concept that in infants, as in adults, nebulised anticholinergic agents act predominantly on the large central airways, ${ }^{34}$ with little effect on more peripheral airways function. Such agents may have more peripheral effect when administered intravenously. ${ }^{3}$ Our results could also be explained by a reduction in nasal resistance, although we have no direct measurements. In adults, however, nebulised ipratropium has no direct effect on nasal airways resistance. ${ }^{13}$

Our results help explain the discrepancy between the reported alleviation of airways obstruction, as measured by an improvement in lung mechanics, and the lack of appreciable clinical benefit shown in a clinical trial of ipratropium bromide in acutely wheezy infants. ${ }^{2}$ Variables of airways function primarily used in this age group include pulmonary resistance and airways resistance, which are both measured during the inspiratory phase of tidal breathing.

Upper and large, central airways contribute about $75 \%$ of the value of pulmonary or airways resistance in normal infants, so that an improvement in these variables after treatment with ipratropium bromide may occur without any improvement in peripheral airways function. In contrast, during an acute attack of wheeze, infants breathe actively, seeming to use forced expiration. Under these circumstances, expiratory flow will be limited by peripheral airways function, and the appropriate laboratory measurement that most closely mimics the natural pattern of breathing is the forced expiratory flow volume curve, which was unaffected by ipratropium bromide.

Physiological considerations. There are other explanations for the discrepancy between the significantly improved airways resistance that we found and the lack of improvement in maximum flow at low lung volumes. Airway resistance measurements are determined by the calibre of the airways from nose to lung periphery. Maximum expiratory flow at any lung volume is determined by the elastic recoil pressure of the lungs, the density of the expired gas, and the calibre and compliance of the airways. The elastic recoil pressure of the lungs has been shown to remain constant after treatment with nebulised anticholinergic agents. ${ }^{3}$

For a constant gas density, maximum flow is then determined by the calibre and compliance of the airways. Should an increase in calibre be equally matched by an increased compressibility of the peripheral flow limiting airways at low lung volumes, such that maximum flow remained constant, no increase in maximum flow at functional residual capacity would be detected, despite a reduction in airways resistance during quiet breathing. It seems unlikely, however, that these effects should be so equally matched as to show no change. It is more likely, as previously shown in adult subjects, that nebulised anticholinergic agents, in 
contrast to intravenous atropine, have minimal effect on peripheral structures in the lung. ${ }^{3}$

Another explanation for the lack of improvement in Vmax FRC could be a change in the absolute lung volume at functional residual capacity such that, if the lungs became less hyperinflated after ipratropium, Vmax FRC was being measured at a lower lung volume than before treatment. Measurements of thoracic gas volume were made before and after treatment with ipratropium. In the 13 completed sets of measurements the mean (SD) values of thoracic gas volume were $199(64) \mathrm{ml}$ and $198(62)$ $\mathrm{ml}$, respectively. Though measurements of thoracic volume are notoriously unreliable in wheezy individuals, ${ }^{10} 11$ it seems unlikely from these results that a fall in absolute lung volume was masking a true improvement in peripheral airways function.

Clinical implications and conclusions. Ipratropium bromide seemed to have its major effect on central or upper airways, as in older subjects. This may explain its limited clinical role as a bronchodilator agent in the presence of pronounced peripheral airways obstruction, as in bronchiolitis. There seems little clinical or physiological support for the widespread use of nebulised ipratropium bromide in the managément of wheezy infants, although it is possible that some individuals may obtain some benefit.

We are grateful to Mr Jimmy Messeguer and Mr Norman Levy for technical help. The work was supported by grants from the Hammersmith and Queen Charlotte's Hospitals SHA, Allen and Hanbury's, and the Asthma Research Council.

\section{References}

${ }^{1}$ Hodges IGC, Groggins RC, Milner AD, Stokes GM. Broncho- dilator effect of inhaled ipratropium bromide in wheczy toddlers. Arch Dis Child 1981:56:729-32.

2 Henry RL. Milner AD. Stokes GM. Ineffectiveness of ipratropium bromide in acute bronchiolitis. Arch Dis Child 1983:58:925-6.

3 De Trover A, Yernault JC, Rodenstein D. Effects of vagal blockage on lung mechanics in normal man. J Appl Physiol 1979:46:217--26

+ Nadel JA, Barnes PS. Autonomic regulation of the airways. Annu Rev Med 1984:35:451-67.

5 Taussig LM, Landau LI. Godfrey S, Arad I. Determinants of forced expiratory flow in newborn infants. J Appl Physiol 1982:53:1220-7.

- Silverman M. Prendiville A. Green S. Partial expiratory flow volume curves in infancy: technical aspects. Bull Eur Phy. siopathol Respir 1986;22:257-62.

7 Stocks J, Levy NM, Godfrey S. A new apparatus for the accurate measurement of airway resistance in infancy. $J$ Appl Physiol 1977:43:155-9

* Stocks J. Thomson A. Silverman M. The numerical analysis of pressure-flow curves in infancy. Pediatr Pulmonology 1985:1: $19-26$

"Stocks J. The functional growth of the lung during the first year of life. Early Hum Dev 1977:1:285-309.

11) Rodenstein DO, Stanescu DC, Francis C. Demonstration of failure of body plethysmography in airways obstruction. $J$ Appl Phvsiol 1982:52:949-54.

1 Godfrey S, Beardsmore C. Maayan C. Bar-Yishay E. Can thoracic gas volume be measured in infants with airways obstructiôn? Am Rev Respir Dis 1986;133:245-51.

12 Dab I, Alexander F. On the advantages of specific airway resistance. Pediatr Res 1978:12:878-81.

13 Sanwikarja S, Schmitz DM, Dieges PH. The effect of locally applied ipratropium acrosal on nasal methacholine challenge in patients with allergic and non-allergic rhinitis. Ann Allergy 1986:56:162-6.

Correspondence to $\mathrm{Dr} M$ Silverman. Department of Paediatrics and Neonatal Medicine. Royal Postgraduate Medical School Hammersmith Hospital, Du Cane Road, London W12 OHS.

Received 7 October 1986 